\title{
Effects of Host, Inoculum Concentration, Wetness Duration, Growth Stage, and Temperature on Anthracnose of Lentil
}

\author{
G. Chongo and C. C. Bernier, Department of Plant Science, University of Manitoba, Winnipeg, Manitoba, R3T \\ 2N2, Canada
}

\begin{abstract}
Chongo, G., and Bernier, C. C. 2000. Effects of host, inoculum concentration, wetness duration, growth stage, and temperature on anthracnose of lentil. Plant Dis. 84:544-548.

The effects of concentration of conidia, duration of the wetness period, plant growth stage, and temperature on the development of anthracnose (Colletotrichum truncatum) on lentil (Lens culinaris) were assessed in growth-chamber and greenhouse studies using cv. Indianhead and line 458-57, which have partial resistance, and susceptible cv. Eston. Each genotype was assessed for incubation period (IP), latent period (LP), number of lesions (LN) per stem, and disease severity (DS). Both IP and LP decreased linearly with increasing conidial concentration, wetness duration, and temperature. Both IP and LP also became progressively shorter as the plants aged between 2 to 6 weeks and increased between 6 to 8 weeks after seeding. Both LN and DS increased linearly with increasing inoculum concentration, wetness duration, and temperature. Both LN and DS also increased with plant age between 2 to 4 weeks and decreased between 4 to 8 weeks. The growth stage and temperature required for optimal disease development ranged, respectively, from 4 to 6 weeks and 20 to $24^{\circ} \mathrm{C}$ when plants were inoculated at a concentration of $4 \times 10^{4}$ conidia/ml and provided with a wetness period of $24 \mathrm{~h}$. Generally, cv. Indianhead and line 458-57 had significantly longer IP and LP and lower LN and DS than cv. Eston.
\end{abstract}

Additional keywords: Colletotrichum truncatum, Lens culinaris, partial resistance

Anthracnose caused by Colletotrichum truncatum (Schwein.) Andrus \& W. D. Moore is one of the major diseases of lentil (Lens culinaris Medik.) in western Canada. The occurrence of anthracnose in Manitoba lentil fields has increased in the past few years, mainly due to increasing levels of inocula left in the field, which then spread to previously uninfested fields through residues carried by wind and splashing rain (2). Infections by $C$. truncatum can occur at any growth stage and on all aboveground plant parts. Lesions usually become visible in the field just before or during early flowering and, as the disease progresses, plants may wilt and die $(2,4)$. Infections remain latent during the early vegetative stage (4).

Anthracnose of lentil can result in significant yield reductions $(5,11)$, particularly under conditions of high rainfall and warmer temperatures (around $20^{\circ} \mathrm{C} ; 1,4$ ). Resistant cultivars are not available and most studies on controlling lentil anthracnose have focused on using fungicides, with some success $(2,4,5)$. Crop rotations of at least 4 years have also been recom-

Corresponding author: C. C. Bernier

E-mail: Bernier@Ms.umanitoba.ca

Accepted for publication 7 January 2000.

Publication no. D-2000-0315-01R

(C) 2000 The American Phytopathological Society mended due to the long survival of $C$. truncatum on crop debris (2). Temperature, duration of wetness period, and inoculum density, in addition to host and pathogen genotypes, affect infection and development of anthracnose diseases of other crops $(13,14)$. Only one study has dealt with the effect of environmental factors on lentil anthracnose. A minimum period of $16 \mathrm{~h}$ of leaf wetness and temperatures greater than $15^{\circ} \mathrm{C}$ were required for anthracnose development (4). Although important to the epidemiology of lentil anthracnose, the effects of growth stage and inoculum density on anthracnose development have not been investigated.

More detailed studies on the effects of environmental factors on anthracnose of lentil could provide a better understanding of the disease and lead to better diseasemanagement practices and more effective protocols for the evaluation of lentil genotypes for resistance.

The objective of the study was to investigate the effects of inoculum concentration, wetness period, temperature, and growth stage on the development of anthracnose on three lentil genotypes in the growth room and greenhouse.

\section{MATERIALS AND METHODS}

Plant material. Line 458-57 and cv. Indianhead, which have partial resistance to lentil anthracnose, and susceptible cv. Eston were used in the study. Seeds of each genotype were planted in 0.5 -liter plastic pots containing soil, sand, and peat in a $2: 1: 1(\mathrm{vol} / \mathrm{vol} / \mathrm{vol})$ mixture for the studies involving inoculum concentration, leafwetness duration, and growth stage. In the temperature study, Metro-Mix (W. R. Grace and Co. Canada, Ltd. Ajax, Ontario, Canada) was used as the planting medium in the same plastic pots. Eight seeds were planted per pot, and seedlings were thinned to five per pot after germination. The pots were kept in the growth chamber, maintained at 20 and $16^{\circ} \mathrm{C}$ (day and night, respectively) with a $16-\mathrm{h}$ photoperiod and 250 to $300 \mu \mathrm{mol} \mathrm{m}{ }^{-2} \mathrm{~s}^{-1}$ photon flux density provided by a mixture of cool white and Vita-Lite fluorescent lamps (Philips Lighting Co., Somerset, NJ, and Duro-test Corp., North Bergen, NJ, respectively). The plants were fertilized weekly with a 20:20:20 (N:P:K) liquid fertilizer.

Inoculum preparation. An isolate of $C$. truncatum (JPPTNL 882) obtained from a lentil field in Manitoba was used in all experiments. A single spore culture was raised on sodium-chloride yeast agar sucrose (SYAS) medium (10) supplemented with $10 \mathrm{ml} /$ liter each of the antibiotics chlortetracycline hydroxide and streptomycin sulfate prepared as 0.52 and $1.39 \mathrm{~g} / 100$ $\mathrm{ml}$ of sterile distilled water, respectively. The final antibiotics concentration in the media was $0.052 \mathrm{ml}^{-1}$ chlortetracycline hydroxide and $0.139 \mathrm{ml}^{-1}$ streptomycin.

Cultures of $C$. truncatum were raised on SYAS medium at room temperature under continuous white fluorescent light. Conidia from 7-day-old cultures were scraped from the Petri dishes using a sterile glass slide and suspended in sterile distilled water. The conidial suspension was then filtered through a layer of Mira-Cloth (Calbiochem-Behring Corp., La Jolla, CA) and conidial concentration was determined using a hemacytometer. The conidial suspension was diluted with sterile distilled water to obtain the final concentrations required for each experiment.

Inoculum concentration study. The effect of inoculum concentration was investigated by inoculating 4-week-old plants (8- to 10-node stage) with suspensions containing $2 \times 10^{4}, 4 \times 10^{4}, 6 \times 10^{4}, 8 \times$ $10^{4}$, and $1 \times 10^{5}$ conidia/ml using a DeVilbis Atomizer (Somerset, PA). Tween 20 (1 drop/100 $\mathrm{ml}$ of spore suspension) was added as wetting agent. Control plants were sprayed with distilled water and Tween 20 (1 drop/100 ml). Inoculated plants were placed in an incubation cham- 
ber where continuous wetness of plants was ensured for $24 \mathrm{~h}$ by misting with a humidifier. The incubation chamber consisted of a steel frame covered with a clear polyethylene sheet and kept at a temperature of approximately $20^{\circ} \mathrm{C}$ with a $16-\mathrm{h}$ photoperiod provided by fluorescent lamps outside the chamber. After incubation, plants were kept in the greenhouse at 20 and $16^{\circ} \mathrm{C}$ (day and night, respectively) with a 16-h photoperiod. Plants were arranged on a greenhouse bench as a 3-by-6 factorial in a randomized complete block design (RCBD) with four replicates and three pots of each genotype per replicate. The experiment was repeated twice.

Wetness duration study. Plants (4 weeks old) were inoculated with a suspension of $4 \times 10^{4}$ conidia/ml and incubated under continuous plant wetness periods of $6,12,24,36$, and $48 \mathrm{~h}$ in a misting chamber. Control plants sprayed with water were not incubated in the misting chamber, but were immediately transferred to the greenhouse after inoculation. Incubated plants were kept in the greenhouse under conditions described above and arranged together with control plants as a 3-by-6 factorial in a RCBD with four replicates and two pots of each genotype per replicate. The experiment was repeated once.

Growth stage study. Four growth stages were used: seedling, 8 to 10 nodes, flowering, and early pod stage (or 2, 4, 6, and 8 weeks after seeding, respectively). Seeding dates were staggered to inoculate plants of different growth stages at the same time.

At each seeding date, cv. Indianhead was sown first, followed by line $458-57$ and $\mathrm{cv}$. Eston 3 and 5 days later, respectively, to synchronize their growth stages based on differences in the time to first flowering. Plants were inoculated with a concentration of $4 \times 10^{4}$ conidia/ml, incubated for 24 $\mathrm{h}$ in the misting chamber, then transferred to the greenhouse, where pots were placed as a 3-by-4 factorial in a RCBD with four replicates consisting of two pots of each genotype per replicate. The experiment was repeated once.

Temperature study. At 4 weeks after seeding, plants were inoculated with a suspension of $4 \times 10^{4}$ conidia $/ \mathrm{ml}$ and provided with a 24 -h continuous plant-wetness period as described above. Following incubation, the plants were kept in different growth chambers at the following temperatures: 16 and 12, 20 and 16, 24 and 20, and 28 and $24^{\circ} \mathrm{C}$ (day and night, respectively) each with a 16-h photoperiod and 250 to $300 \mu \mathrm{mol} \mathrm{m} \mathrm{m}^{-2} \mathrm{~s}^{-1}$ photon flux density. The experiment was designed as a split plot with temperature as main plot and genotypes as subplot factors. There were two pots of each genotype at each temperature. To provide three more replicates, the experiment was repeated three times.

Anthracnose rating. In all experiments, stem tissue was used to assess incubation period (IP), latent period (LP), lesion number (LN) per stem, and disease severity (DS). The IP was defined as the time in days from inoculation to the appearance of lesions on stems and LP as the time in days from inoculation to the formation of acervuli in the lesions. A 10 to $20 \times$ hand lens was used to observe acervuli. Observations for IP and LP were done every day beginning, the third day after inoculation. The LN was determined by counting all visible lesions on the main stem 4 weeks after inoculation. The DS was also determined 4 weeks after inoculation using a rating scale of 0 to 3 modified from Graham et al. (6), where $0=$ stems with no lesions, $1=$ stems with few superficial lesions, $2=$ stems with many deep lesions not girdling the stem, and 3 = stems with many deep coalescing lesions girdling the stem. Percent DS was then calculated using the following formula: $\% D S=\{[\Sigma$ (no. of plants/scale $\times$ scale value $)] /[$ highest scale $\times$ total no. of plants] $\} \times 100$.

Analysis. Data for the effect of conidial concentration, wetness duration, and temperature on IP, LP, LN, and DS was subjected to analysis of variance (ANOVA) with orthogonal polynomials when necessary, mainly to determine the significance of main effects and their interactions. Regression analysis was used to fit the linear models. Data for conidial concentration was transformed to the natural logarithmic scale before analysis. In the regression

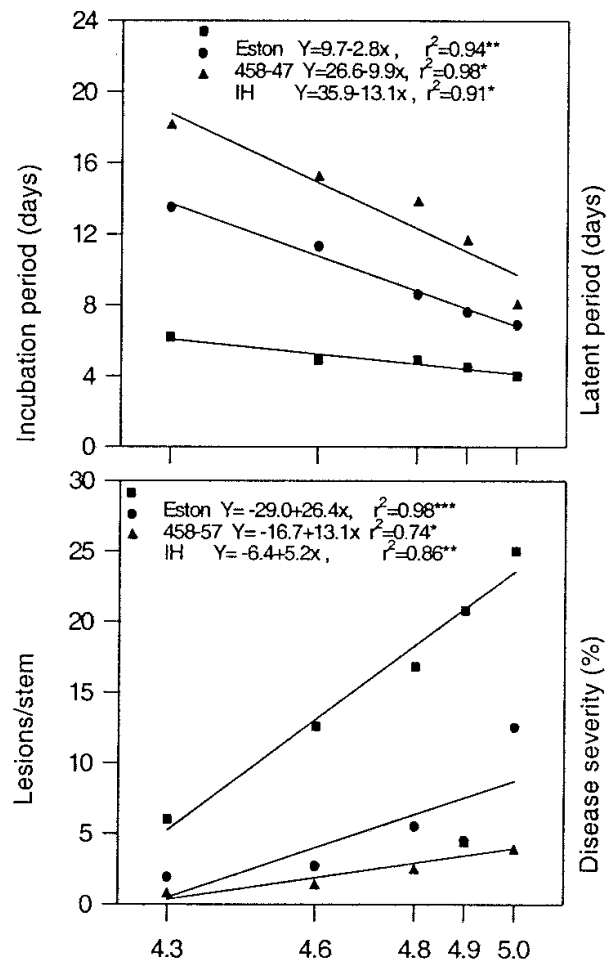

Ln conidial concentration analysis, scatter plots of residuals with predicted values, from regression lines and standardized residuals computed by dividing residuals by their respective standard errors, were visually inspected for possible violations of the assumptions of normal distribution, but they were normally distributed.

Analysis of the effects of growth stage on IP, LP, LN, and DS were performed by using ANOVA and mean comparisons were done by using the least significant difference (LSD, $P=0.05$ ). Bartlett's homogeneity tests for experimental variances performed on all variables indicated homogenous error variances and, therefore, allowed pooling of data over experiments. For the temperature and growth-stage studies, ANOVA tables were included showing only important components. All analyses were done using the Statistical Analysis System (SAS, Institute Inc., Carry, NC).

\section{RESULTS}

Inoculum concentration. ANOVA showed that conidial concentration and genotype had significant effects on IP, LP, LN, and DS $(P=0.0001)$. For IP, LN, and DS, the interaction between genotype and concentration was also significant $(P \leq$ $0.05)$, indicating a dependence of anthracnose development on genotype and conidial concentration. The effects of inoculum concentration on anthracnose development are
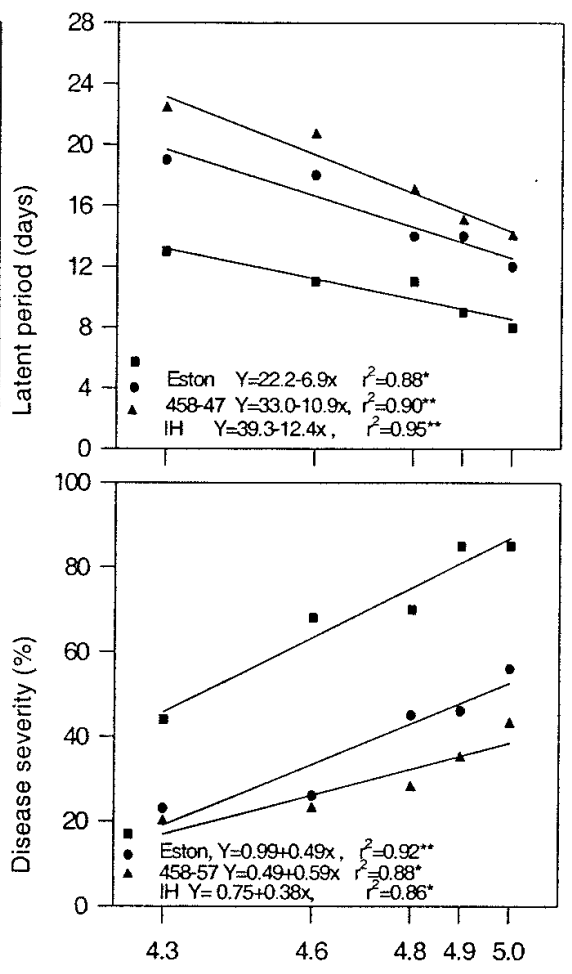

Ln conidial concentration

Fig. 1. Effect of log conidial concentration on incubation period, latent period, lesion number per stem, and disease severity on three lentil genotypes inoculated with isolate JPPTNL 882 of Colletotrichum truncatum from three experiments; *, **, and $* * *=$ significant at $P=0.05,0.01$, and 0.001 , respectively. 
presented as regression of means of IP, LP, LN, and DS against log conidial concentration (Fig. 1). Both IP and LP decreased linearly as $\log$ conidial concentration increased in all genotypes, but IP and LP were shortest in cv. Eston, intermediate in line 458-57, and longest in cv. Indianhead at each concentration rate. The coefficients of determination $\left(r^{2}\right)$ ranged from 0.94 to 0.98 for IP and 0.88 to 0.95 for LP for all three genotypes.

On the other hand, LN and DS increased linearly with increased log conidial concentration. $\mathrm{Cv}$. Eston had the highest LN and displayed more disease compared to line 458-57 or cv. Indianhead (Fig. 1). The
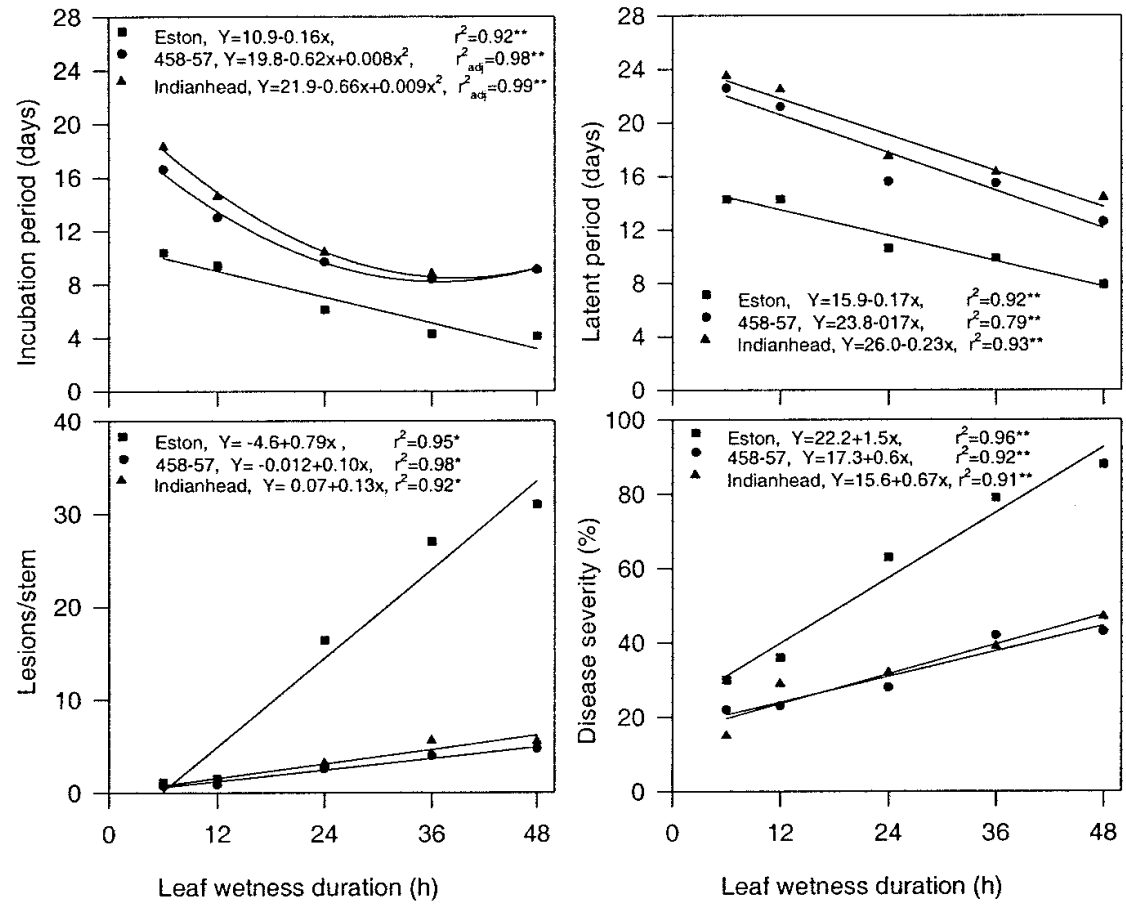

Fig. 2. Effect of wetness duration on incubation period, latent period, lesion number per stem, and disease severity on three lentil genotypes inoculated with isolate JPPTNL 882 of Colletotrichum truncatum from two experiments; $*$ and $* *=$ significant at $P=0.05$ and 0.01 , respectively.
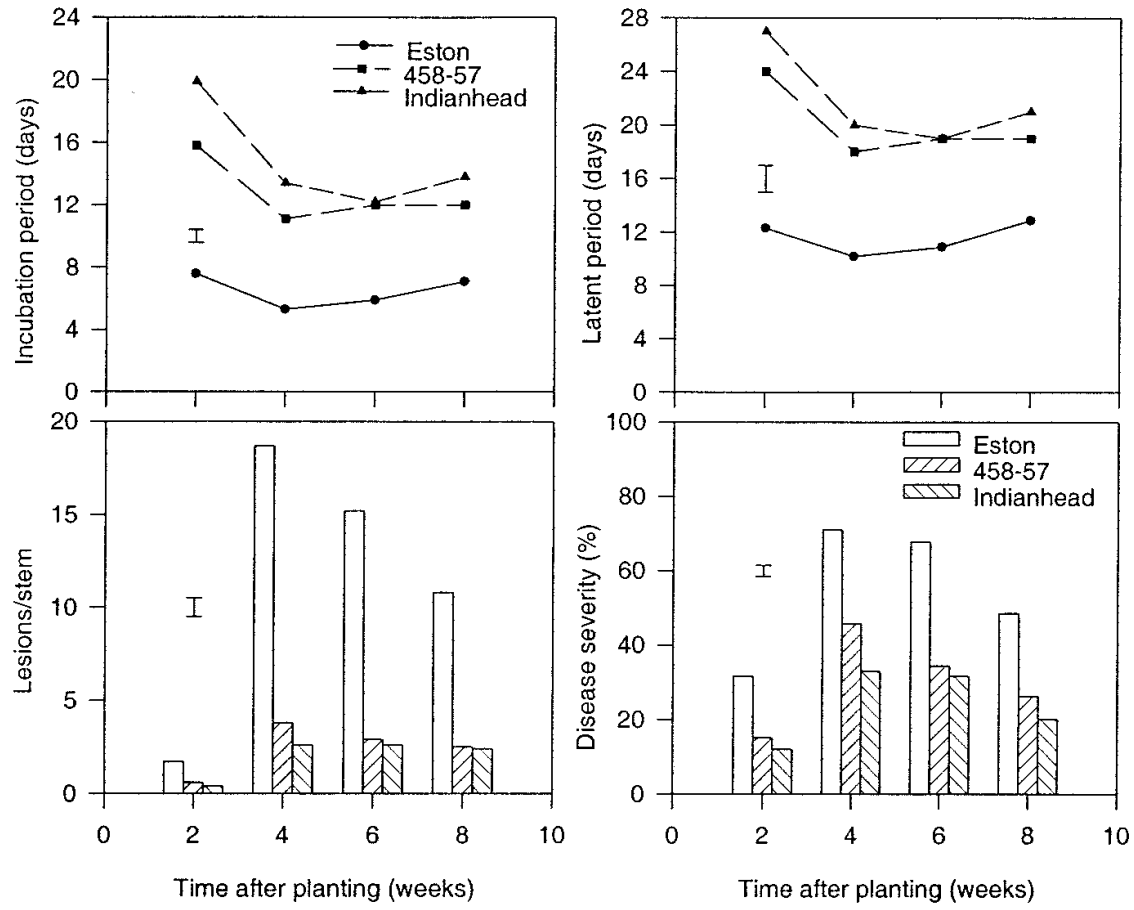

Fig. 3. Effect of host growth stage on incubation period, latent period, lesion number per stem, and disease severity on three lentil genotypes inoculated with isolate JPPTNL 882 of Colletotrichum truncatum from two experiments. Bar = standard error of the difference. $r^{2}$ values among the three genotypes ranged from 0.74 to 0.98 and 0.86 to 0.92 for LN and DS, respectively. All the models were significant at $P \leq 0.05$, indicating that $\log$ conidial concentration explained most of the variability in IP, LP, LN, and DS. Control plants inoculated with distilled water and Tween 20 showed no symptoms.

Wetness duration. Wetness duration and genotype had a significant (ANOVA, $P$ $=0.0001$ ) effect on anthracnose development. The interaction between wetness duration and genotype was only significant $(P \leq 0.001)$ for LN and DS. Control plants without a wetness period were not infected. When the wetness period was increased from 6 to $48 \mathrm{~h}$, the length of IP for cv. Eston decreased linearly, while IP for cv. Indianhead and line 458-57 were best described by quadratic functions $(P<0.009)$. Latent period for all three genotypes decreased linearly $(P<0.01)$ with increase in wetness duration (Fig. 2).

The LN and DS were lowest for all three genotypes when wetness duration was $6 \mathrm{~h}$, but both increased linearly as the wetness period increased to $48 \mathrm{~h}$ (Fig. 2). The $r^{2}$ values for IP, LP, LN, and DS among the genotypes were significant $(P<0.05)$ and ranged from 0.79 to 0.99 . Lesion number was not significantly different among the three genotypes at the 6- or 12 -h wetness period. $\mathrm{Cv}$. Eston had the highest DS at each wetness period.

Growth stage. The main effects due to growth stage and genotype had significant (ANOVA, $P=0.0001$ ) effects on IP, LP, $\mathrm{LN}$, and DS. The interactions between genotypes and growth stages were significant for IP, LP, LN, and DS $(P=0.001)$, showing that the differences among the host genotypes for these factors were significantly dependent on growth stage and genotype.

Incubation period was longest $(7.6,15.8$, and 19.9 days for cv. Eston, line 458-57, and cv. Indianhead, respectively) when plants were 2 weeks old (Fig. 3). However, as plants became older, IP decreased to 5.3, 11.1, and 12.2 days at 4 weeks in Eston and $458-57$ and at 6 weeks in Indianhead, respectively. At 8 weeks, IP increased in each genotype (Fig. 3). Similarly, LP initially decreased with increase in plant age from 27, 24, and 13.9 days in Indianhead, 458-57, and Eston at 2 weeks, respectively, to a low of 20 days at 6 weeks in Indianhead, 18 days at 4 weeks in 458-57, and 10.2 days at 4 weeks in Eston. Slight increases in IP an LP were observed between 4 and 8 weeks in all three genotypes.

The lowest LN was found in 2-week-old plants, but LN increased significantly with plant age (reaching the highest levels at 4 weeks in all three genotypes), then slightly decreased after 4 weeks (Fig. 3). Disease severity was lowest on 2-week-old plants (31.6\% in cv. Eston, $15.1 \%$ in line 458-57, and $12.4 \%$ in cv. Indianhead), but increased with plant age to maximum levels 
(71, 45.8, and 33\% in Eston, 458-57, and Indianhead, respectively) at 4 weeks (Fig. 3). Eston had significantly higher $\mathrm{LN}$ and DS than Indianhead and 458-57 at each growth stage. However, in Indianhead and 458-57, LN and DS were not significantly different at any growth stage except at 4 weeks.

Temperature. Both IP and LP were longest at $16^{\circ} \mathrm{C}$ but decreased linearly with increasing temperature for each genotype (Fig. 4). The significant regression of IP and LP $\left(r^{2}=0.82\right.$ to $\left.0.99, P \leq 0.05\right)$ on temperature indicated that most of the
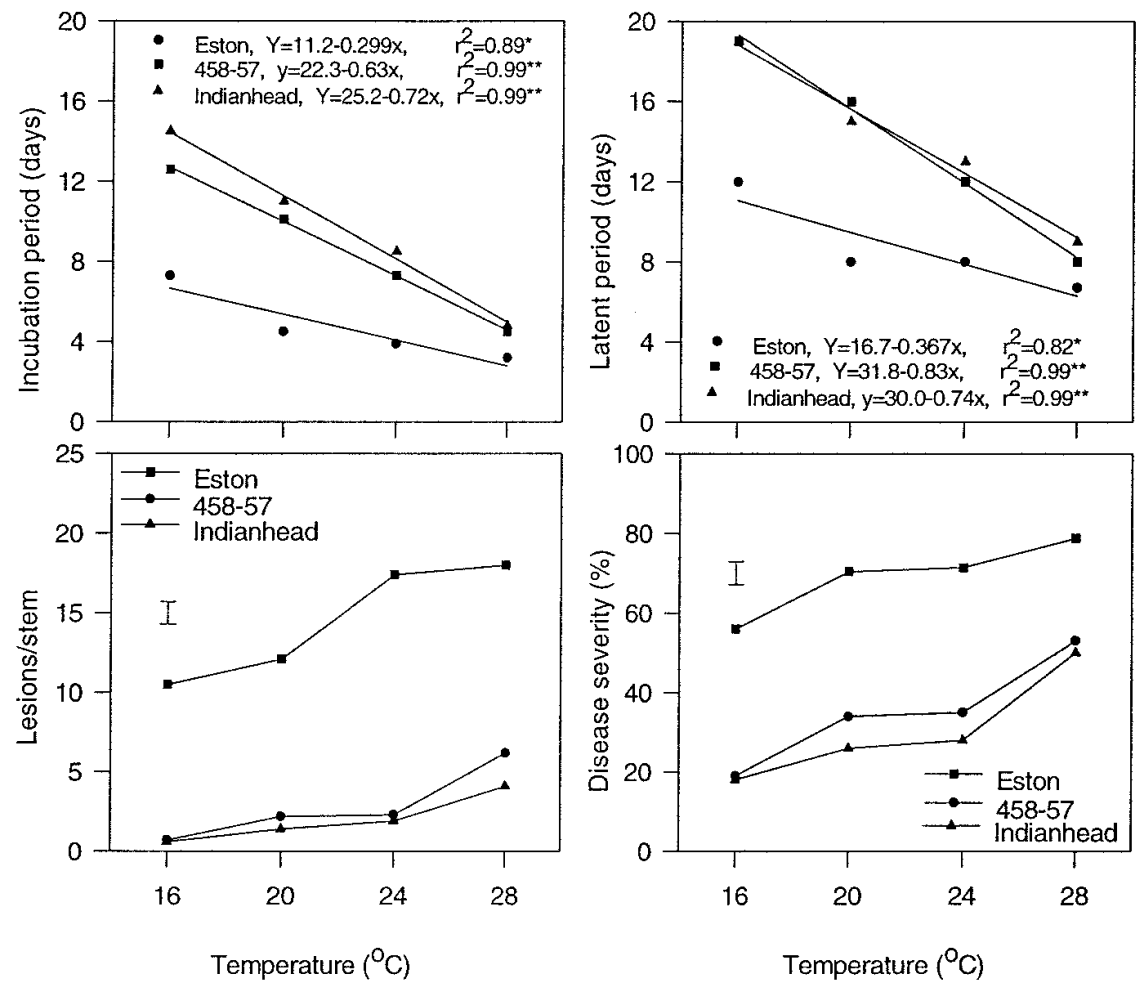

Fig. 4. Effect of temperature on incubation period, latent period, lesion number per stem, and disease severity on three lentil genotypes inoculated with isolate JPPTNL 882 of Colletotrichum truncatum from two experiments. $\mathrm{Bar}=$ standard error of the difference; $*$ and $* *=$ significant at $P=0.05$ and 0.01 , respectively.

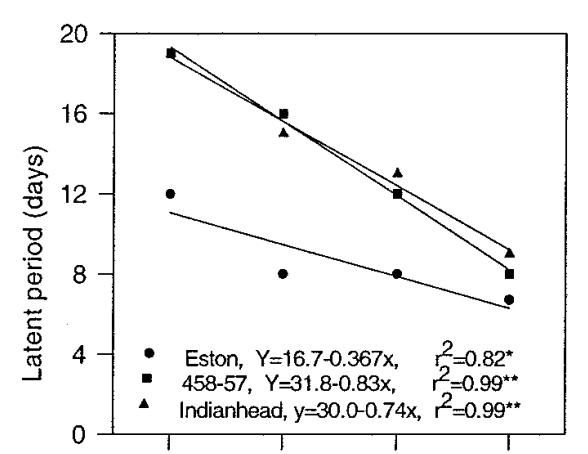

variability within each genotype was explained by the regression line.

ANOVA and orthogonal polynomials and contrasts showed that temperature $(T)$ and host genotype $(G)$ had significant effects $(P \leq 0.001)$ on IP, LP, LN, and DS (Table 1, Fig. 4). The linear and quadratic polynomials for $\mathrm{LN}$ and only the linear polynomial for DS were significant (Table 1). For $\mathrm{LN}$, the linear component sum of indicating that LN, as did DS, increased linearly with increasing temperature. The interaction between $T$ and $G$ was also sigsquares contributed much of the variation, nificant $(P \leq 0.01)$ for $\mathrm{LN}$; therefore, the sum of squares for $T$ and $T \times G$ interaction were partitioned into single degree contrast sum of squares (Table 1) to determine the important polynomials. The $T_{\text {linear }} \times G$ interaction accounted for most of the variability for each genotype (Table 1).

Lesion number was lowest at $16^{\circ} \mathrm{C}$ but increased as temperature was increased to $28^{\circ} \mathrm{C}$ in all three genotypes (Fig. 4). Cv. Eston had significantly higher LN across the temperature range (10.5 to 18$)$ compared to cv. Indianhead and line 458-57 (0.6 to 6.2). The number of lesions per stem at each temperature for Indianhead and 458-57 were not different except at $28^{\circ} \mathrm{C}$, where $\mathrm{LN}$ was significantly higher on 458-57. Disease severity was also lowest at $16^{\circ} \mathrm{C}$, but increased as temperature was increased, reaching the highest levels at $28^{\circ} \mathrm{C}$ in each genotype (Fig. 4). The DS was always significantly higher on Eston than on Indianhead and 458-57 at each temperature, but DS values on Indianhead and 458-57 were not significantly different at any temperature.

\section{DISCUSSION}

The development of anthracnose on lentil can be influenced by host genotype, inoculum concentration, the duration of wetness period, growth stage, and temperature. This study demonstrated that all of these factors had significant effects on anthracnose. For LN and DS, the effect of each factor was greater on cv. Eston than on cv. Indianhead and line 458-57. On the other hand, the effects of each factor on IP and LP were greater on 458-57 and Indianhead than Eston. For each factor, both Indianhead and 458-57 reacted similarly to infection by $C$. truncatum compared to Eston.

Increasing conidial concentrations from $2 \times 10^{4}$ to $1 \times 10^{5}$ conidia/ml linearly decreased the time required for lesions to develop on stems and the time to first sporulation, and increased LN and DS on

Table 1. Analysis of variance for incubation period, latent period, lesion number, and disease severity in three lentil genotypes as affected by growth stage and temperature after inoculation with isolate JPPTNL 882 of Colletotrichum truncatum

\begin{tabular}{|c|c|c|c|c|c|}
\hline \multirow[b]{2}{*}{ Source } & \multirow[b]{2}{*}{ DF } & \multicolumn{4}{|c|}{ Mean squares $^{\mathbf{a}}$} \\
\hline & & IP & $\mathbf{L P}$ & LN & DS \\
\hline Genotype (G) & 2 & $1,227 * * *$ & $1,925 * * *$ & $1,884 * * *$ & 16460 *** \\
\hline Stage (S) & 3 & $215 * * *$ & $242 * * *$ & $502 * * *$ & $8803 * * *$ \\
\hline $\mathrm{G} \times \mathrm{S}$ & 6 & $32 * * *$ & $38 * * *$ & $205^{* *}$ & $388 * * *$ \\
\hline Error & 173 & 6 & 8 & 8 & 76 \\
\hline Temperature (T) & 3 & $\ldots$ & $\ldots$ & $137 * * *$ & $3586^{* * *}$ \\
\hline $\mathrm{T}_{\text {linear }}$ & 1 & $\ldots$ & $\ldots$ & $407 * * *$ & $9900 * * *$ \\
\hline $\mathrm{T}_{\text {quadratic }}$ & 1 & $\ldots$ & $\ldots$ & 5 & 57 \\
\hline $\mathrm{T}_{\text {cubic }}$ & 1 & $\ldots$ & $\ldots$ & 0 & $801 *$ \\
\hline Error A & 9 & $\ldots$ & $\ldots$ & 3 & 126 \\
\hline $\mathrm{G}$ & 2 & $\ldots$ & $\ldots$ & $1,557 * * *$ & $14139 * * *$ \\
\hline $\mathrm{G} \times \mathrm{T}$ & 6 & $\ldots$ & $\ldots$ & $19 * *$ & 126 \\
\hline $\mathrm{T}_{\text {linear }} \times \mathrm{cv}$. Eston & 1 & $\ldots$ & $\ldots$ & $309^{* * * *}$ & $\ldots$ \\
\hline $\mathrm{T}_{\text {linear }} \times$ line $458-57$ & 1 & $\ldots$ & $\ldots$ & $109^{* * * *}$ & $\ldots$ \\
\hline $\mathrm{T}_{\text {linear }} \times \mathrm{cv}$. Indianhead & 1 & $\ldots$ & $\ldots$ & $47 * * *$ & $\ldots$ \\
\hline Error B & 72 & $\ldots$ & $\ldots$ & 3 & 128 \\
\hline
\end{tabular}

a IP = incubation period, $\mathrm{LP}=$ latent period, $\mathrm{LN}=$ lesion number, and DS = disease severity; $* * *$, and $* * *=$ significant at $P=0.05,0.001$, and 0.0001 , respectively. 
all genotypes. Although the rates of change in IP and LP as affected by log conidial concentration were greater in cv. Indianhead and line 458-57, anthracnose severity was greater on cv. Eston due to a higher infection frequency. When conidial concentration was higher than $6 \times 10^{4}$ con$\mathrm{idia} / \mathrm{ml}$, most plants of the susceptible cultivar died, with anthracnose severity reaching about $85 \%$ within 1 to 2 weeks after inoculation. However, the same concentration only resulted in severities ranging from 46 to $56 \%$ on line $458-57$ and 35 to $43 \%$ on cv. Indianhead and did not result in plant death. In a similar study by Chakraborty (3), DS in Stylosanthes spp. in response to $C$. gloeosporioides also increased with conidial concentration to an optimum level and decreased at higher concentrations. Makowski (9) reported increased DS and high plant mortalities in round-leaved mallow (Malva pusilla Smith), with increases in spore concentrations of C. gloeosporioides. Plant death in cv. Eston in the present study occurred at inoculum concentrations greater than $6 \times$ $10^{4}$ conidia/ml; therefore, in subsequent studies involving wetness period, growth stage, and temperature, a concentration of $4 \times 10^{4}$ conidia/ml was used in order to allow assessment of LP in all genotypes.

Wetness period had a significant effect on anthracnose development. Inoculated plants given a 6- or 12-h wetness period took longer to show symptoms and to sporulate, and few lesions were produced on all three genotypes ( 0.8 to 1.1 lesions/stem on cv. Indianhead and line 45857 and 1.1 to 1.5 on cv. Eston). Severe disease was only observed when plants were provided with at least a 24 -h wetness period. Although the IP for all genotypes decreased as the wetness period was extended to $48 \mathrm{~h}$, the reductions in the IP for Indianhead and 458-57 were less than in Eston as wetness period increased beyond $24 \mathrm{~h}$. Eston was most affected by longer wetness periods; the infection frequency increased from 1 to 31 lesions/stem when the wetness period was prolonged from 6 to $48 \mathrm{~h}$, compared to an increase of 0.75 to 6 lesions/stem for Indianhead and 458-57. Furthermore, when the wetness period was at least $36 \mathrm{~h}$, a DS of about 80 to $88 \%$ resulted in death of most Eston plants within 1 to 2 weeks of inoculation. A 24-h leaf wetness period would appear to be the most effective for comparisons of genotypes.

Plants of all three genotypes inoculated at 2 or 8 weeks after seeding were less susceptible than 4- to 6-week-old plants. Symptoms were more severe on 4- to 6weeks-old plants, and the fact that this growth stage coincides with the start of flowering in the field may partly explain why symptoms more commonly appear during this time $(2,4)$. Most lesions on 2to 6-week-old plants were confined to stem bases but, on 8-week-old plants, lesions were mostly on the upper portions of the plants. A similar finding in lentil infected with Ascochyta fabae f. sp. lentis Gossen et al. has been reported (12). The authors suggested that this resistance was related to tissue age because younger tissues were infected when older plants were inoculated. In the present study, the growthstage-related resistance increased IP and LP and reduced LN and DS more on cv. Indianhead and line 458-57 than on cv. Eston.

When temperature was increased incrementally from 16 to $28^{\circ} \mathrm{C}$, IP and LP decreased linearly, while DS and LN increased with temperature. The decreases in IP or LP with an increase in temperature have also been reported for ascochyta blight of lentil (12) and in strawberry (Fragaria $\times$ ananassa Duchesne) in response to other Colletotrichum spp. (8). Similarly, DS in round-leaved mallow inoculated with $C$. gloeosporioides (9) and in soybean (Glycine max (L.) Merr.) infected with $C$. truncatum (7) increased with temperatures between 10 and $25^{\circ} \mathrm{C}$ and decreased at $30^{\circ} \mathrm{C}$. Tu (14) found that disease severity in beans (Phaseolus vulgaris $\mathrm{L}$ ) inoculated with $C$. lindemuthianum (Sacc. \& Magnus) Lams.-Scrib. was greater at temperatures ranging from 20 to $24^{\circ} \mathrm{C}$ than at lower or higher temperatures. In the present study, lesions appeared later and were fewer at $16^{\circ} \mathrm{C}$ than at temperatures between 20 and $28^{\circ} \mathrm{C}$. The highest number of lesions per stem occurred at $28^{\circ} \mathrm{C}$ in all three genotypes, but lesions were also smaller than at any other temperature. This has also been reported for soybean anthracnose (7). However, the decrease in lesion size with higher temperature in the present study is in contrast to the increase in lesion size with higher temperatures in cucumber (Cucumis sativus L.) anthracnose caused by $C$. lagenarium (Pass.) Ellis \& Halst. (13). In the present study, plants grown at $28^{\circ} \mathrm{C}$ also showed heat scorching and stunting, suggesting that this regime may have adversely affected the physiology and growth of the plants, and that the reduction in lesion size may not be due to increased resistance. Therefore, the optimal temperature for anthracnose development on lentil was considered to be between 20 and $24^{\circ} \mathrm{C}$. The slower rate of symptom development at $16^{\circ} \mathrm{C}$ might also partly explain the delay in appearance of symptoms until early flowering observed in the field. In some years, temperatures below $16^{\circ} \mathrm{C}$, especially at night, are common during early spring, when plants are young. These conditions may also be less favorable to infections by $C$. truncatum.

In conclusion, plants at all growth stages were infected by $C$. truncatum, but the period between 4 and 6 weeks after seeding was optimal for infection in all three genotypes. Plants inoculated with $4 \times 10^{4}$ conidia/ml required a minimum of a $6-\mathrm{h}$ leaf wetness period for infection to occur, but severe anthracnose developed with wetness periods and temperatures of at least $24 \mathrm{~h}$ and $20^{\circ} \mathrm{C}$, respectively. Both IP and LP were longer and LN and DS were lower on the two partially resistant genotypes than on susceptible cv. Eston.

\section{ACKNOWLEDGMENTS}

We thank the Western Grain Research Foundation, Agriculture and Agri-Food Canada/National Sciences and Engineering Research Council, and the Manitoba Pulse Growers Association for financial support; and R. Smith for his technical support.

\section{LITERATURE CITED}

1. Buchwaldt, L., Bernier, C. C., and Platford, R. G. 1993. Anthracnose and other diseases of lentil in Manitoba in 1992. Can. Plant Dis. Surv. 73:88-90.

2. Buchwaldt, L., Morrall, R. A. A., Chongo, G., and Bernier, C. C. 1996. Windborne dispersal of Colletotrichum truncatum and survival in infested lentil debris. Phytopathology 86:1193-1198.

3. Chakraborty, S. 1990. Expression of resistance to Colletotrichum gloeosporioides in Stylosanthes scabra at different inoculum concentrations and day-night temperatures. Aust. J. Agric. Res. 41:89:100.

4. Gibson, R. J. 1994. An investigation into the epidemiology and control of anthracnose (Colletotrichum truncatum) of lentil in Manitoba. MS thesis. The University of Manitoba, Winnipeg, Canada.

5. Gibson, R. J., Bernier, C. C., and Morrall, R. A. A. 1991. Anthracnose of lentil in Manitoba in 1990. Can. Plant Dis. Surv. 71:104.

6. Graham, J. H., Devine, T. E., and Hanson, C. H. 1976. Occurrence and interaction of three species of Colletotrichum on alfalfa in the mid-Atlantic United States. Phytopathology 66:538-541.

7. Khan, M., and Sinclair, J. B. 1991. Effect of soil temperature on infection of soyabean roots by sclerotia-forming isolates of Colletotrichum truncatum. Plant Dis. 75:12821285 .

8. King, W. T., Madden, L. V., Ellis, M. A., and Wilson, L. L. 1997. Effects of temperature and sporulation on latent period of Colletotrichum spp. infecting strawberry fruit. Plant Dis. 81:77-84.

9. Makowski, R. M. D. 1993. Effect of inoculum concentration, temperature, dew period and plant growth stage on disease of round leaved mallow and velvet leaf by Colletotrichum gloeosporioides f. sp. Malvae. Phytopathology 83:1229-1234.

10. Manandhar, J. B., Hartman, G. L., and Sinclair, J. B. 1986. Colletotrichum destructivum, the anamorph of Glomerella glycines. Phytopathology 76:282-285.

11. Morrall, R. A. A., and Pedersen, E. A. 1991 Discovery of lentil anthracnose in Saskatchewan in 1990. Can. Plant Dis Surv. 71:105-106.

12. Pedersen, E. A., and Morrall, R. A. A. 1994 Effect of cultivar, leaf wetness duration, temperature and growth stage on infection and development of ascochyta blight of lentil. Phytopathology 84:1024-1030.

13. Thompson, D. C., and Jenkins, S. F. 1985. Effect of temperature, moisture and cucumber resistance on lesion size and increase and conidial production by Colletotrichum lagenarium. Phytopathology 75:828-832.

14. Tu, J. C. 1992. Colletotrichum lindemuthianum on bean: Population dynamics of the pathogen and breeding for resistance. Pages 203-224 in: Colletotrichum: Biology, Pathology and Control. J. A. Bailey and M. J. Jeger, eds. Redwood Press, Ltd., Melksham, England. 